\title{
EDUCAÇÃO ESPECIAL NO MUNICÍPIO DE NAVIRAÍ-MS: HISTÓRIA, DESDOBRAMENTOS E DESAFIOS PARA A INCLUSÃO ESCOLAR
}

\author{
EDUCACIÓN ESPECIAL EN NA VIRAÍ-MS: HISTORIA, SEGUIMIENTO Y \\ DESAFÍOS PARA LA INCLUSIÓN ESCOLAR
}

\section{SPECIAL EDUCATION IN THE MUNICIPALITY OF NAVIRAÍ-MS: HISTORY, DEVELOPMENTS AND CHALLENGES FOR SCHOOL INCLUSION}

\author{
Felipe ALVES BARBOSA ${ }^{1}$ \\ Ilma Regina Castro SARAMAGO DE SOUZA ${ }^{2}$
}

\begin{abstract}
RESUMO: Este texto objetiva discutir a história e os desdobramentos da Educação Especial no município de Naviraí-MS. Com base na pesquisa qualitativa, a coleta de dados contou com a aplicação de um questionário à Coordenadora de Inclusão, responsável pela Educação Especial do município de Naviraí. Os resultados da pesquisa apontam que, desde os primeiros atendimentos aos alunos com deficiência, a Educação Especial no município de Naviraí teve vários avanços, dentre eles destacam-se: a ampliação do número de atendimento nas SRM e o atendimento específico para alunos com Transtorno do Espectro Autista. Embora, os avanços sejam notórios e a busca pela inclusão escolar esteja presente no sistema educacional de Naviraí, observa-se a necessidade da implementação de novas SEM no município, visto a existência de apenas duas salas para a demanda. Constatou-se a carência de formação e de qualificação para os professores, em especial para aqueles que atuam diretamente com alunos com necessidades especializadas. Contudo, mesmo diante das limitações, verifica-se que o município tem buscado estratégias para que a inclusão escolar seja efetivada entre os alunos, público da Educação Especial.
\end{abstract}

PALAVRAS-CHAVE: Educação especial. Atendimento educacional especializado. Inclusão escolar.

RESUMEN: Este texto tiene como objetivo discutir la historia y los desarrollos de la Educación Especial en la ciudad de Navirai-MS. Con base en la investigación cualitativa, la recolección de datos incluyó la aplicación de un cuestionario al Coordinador de Inclusión, responsable de la Educación Especial de Naviraí. Los resultados de la investigación indican que, desde la primera asistencia a estudiantes con discapacidades, la Educación Especial en Naviraí ha tenido varios avances, entre ellos: el aumento del número de asistencia en SRM y la asistencia específica para estudiantes con Trastorno. Espectro autista. Aunque los avances son notables y la búsqueda de inclusión escolar está presente en el sistema educativo de Naviraí, existe la necesidad de implementar un nuevo SEM en el municipio, ya que solo hay dos salones para demanda. Hubo una falta de

\footnotetext{
${ }^{1}$ Rede Municipal de Ensino (RMA), Naviraí - MS - Brasil. Professor. Especialista em Educação Especial pela Universidade Federal da Grande Dourados (FAED/UFGD). ORCID: https://orcid.org/0000-0002-9860-7497. E-mail: felipe_abarbosa@hotmail.com

${ }^{2}$ Universidade Federal de Mato Grosso do Sul (UFMS), Pioneiros - MS - Brasil. Doutora em Educação pela Universidade Federal da Grande Dourados. Professora contratada na Universidade Federal de Mato Grosso do Sul. Desenvolve pesquisas nas áreas da Educação Escolar Indígena; Dificuldades de Aprendizagem e Inclusão. ORCID: https://orcid.org/0000-00025430-1111. E-mail: ilmasaramago@hotmail.com
} 
capacitación y calificación para los maestros, especialmente para aquellos que trabajan directamente con estudiantes con necesidades especializadas. Sin embargo, incluso frente a las limitaciones, se puede ver que el municipio ha estado buscando estrategias para que la inclusión escolar sea efectiva entre los estudiantes, el público de educación especial.

PALABRAS CLAVE: Educación especial. Servicio educativo especializado. Inclusión escolar.

ABSTRACT: This text aims to discuss the history and developments of Special Education in the municipality of Navirai-MS. Based on the qualitative research, the data collection had the application of a questionnaire to the Coordinator of Inclusion, responsible for Special Education in the municipality of Naviraí. The results of the research indicate that since the first visits to students with disabilities, Special Education in the municipality of Navirai has had several advances, among them the following: the expansion of the number of services in the SRM and the specific care for students with Spectrum Disorder Autistic. Although the advances are notorious and the search for school inclusion is present in the educational system of Naviraí, it is observed the necessity of the implementation of new SRM in the municipality, since there are only two rooms for the demand. There was a lack of training and qualification for teachers, especially for those who work directly with students with specialized needs. However, even in the face of limitations, it is observed that the municipality has sought strategies for school inclusion to be made among, the public education students.

KEYWORDS: Special education. Specialized educational assistance. School inclusion.

\section{Introdução}

A verdadeira educação consiste em pôr a descoberta ou fazer atualizar o melhor de uma pessoa. Que livro melhor que o livro da humanidade? Mahatma Gandhi

As políticas públicas voltadas para a Educação Especial constituem-se em um avanço na história das pessoas com deficiência. Sem a garantia de dispositivos legais como a Constituição Federal brasileira de 1988, a Lei de Diretrizes e Bases de 1996, das Resoluções voltadas para o público com deficiência, entre outros dispositivos, esses alunos, possivelmente, ainda estariam vivendo em situação de segregação, à margem da sociedade. Tais dispositivos legais trouxeram à pessoa com deficiência o respeito à diversidade, que preconizam a potencialidade, a capacidade intelectual de cada um, seus interesses e motivações.

Os alunos deficientes vêm mobilizando tanto a comunidade escolar quanto a sociedade, perante a necessidade de oferecer uma educação de qualidade, em que todos devem estar incluídos nas salas de aulas do ensino regular. As novas perspectivas educacionais para a Educação Especial trazem uma visão sobre a política educacional em 
âmbito estadual e municipal e possibilitam diferentes técnicas metodológicas por parte dos professores, coordenadores e comunidade escolar, considerando as diferentes habilidades dos alunos, gerando condições que permitam o acesso e a participação de todos.

Nesse sentido, esta pesquisa teve como lócus o município de Naviraí, Estado do Mato Grosso do Sul. Seu objetivo pautou-se por discutir a história e os desdobramentos da Educação Especial no município de Naviraí-MS. Com base na pesquisa qualitativa, o instrumento utilizado para a coleta de dados foi um questionário aplicado à Coordenadora de Inclusão, responsável pela Educação Especial do município supracitado. O questionário contou com 13 perguntas abertas ou livres que, conforme Marconi e Lakatos (2003, p. 204), "possibilita investigações mais profundas e precisas" do participante.

Sua fundamentação teórica tem como base os estudos de Mazzotta (2005), Capelline e Mendes (2006), Mendes (2010), bem como documentos legais que contemplam os direitos das pessoas com deficiência. As análises dos dados foram feitas a partir das temáticas: Educação Especial em Naviraí; Atendimento Educacional Especializado; formação de professores para o atendimento na Educação Especial e Inclusão Escolar, cujo conteúdo estava presente no questionário aplicado à gestora supracitada.

O trabalho está dividido em três tópicos: o primeiro deles, intitulado "Panorama histórico da Educação Especial no Brasil e seus dispositivos legais", apresenta um breve histórico da constituição da Educação Especial no Brasil, a implementação das políticas públicas no decorrer dos anos e as perspectivas atuais da Educação Inclusiva. O segundo tópico, "A cidade de Naviraí - lócus da pesquisa", apresenta o município de Naviraí e o sistema educacional da cidade. O terceiro tópico, “A Educação Especial em Naviraí", discute a implementação da Educação Especial no município, seu desenvolvimento, processo e desafios para a inclusão escolar.

Espera-se que a pesquisa venha colaborar para que tanto a Secretaria de Educação quanto as escolas tenham o interesse de refletir e discutir como se tem construído a Educação Especial no município, bem como a inclusão escolar dos seus alunos. Além disso, espera-se que os resultados da pesquisa leve a sociedade a respeitar os princípios legais para os deficientes, proporcionando-lhes condições para que tenham qualidade de vida, seja no âmbito social, educacional e profissional.

\section{Panorama histórico da Educação Especial no Brasil e seus dispositivos legais}

A história da Educação Especial no Brasil teve seu começo no século XIX. Com 
início na Europa e nos Estados Unidos da América, estendeu-se por diferentes países, entre eles o Brasil, com a criação de institutos para o atendimento de pessoas cegas, surdas, deficientes mentais e deficientes físicos. Divididos por três períodos distintos, passou pela iniciativa privada (1854 a 1959); por ações oficiais de âmbito nacional (1957 a 1993); e atualmente passa pelo movimento em favor da inclusão.

Os primeiros atendimentos às pessoas com deficiência ocorreram no período Imperial com a criação de duas instituições: o Imperial Instituto dos Meninos Cegos, em 1854, atual Instituto Benjamin Constant (IBC), e o Instituto dos Surdos-Mudos, em 1857, atual Instituto Nacional da Educação dos Surdos (INES), ambos no Rio de Janeiro (MAZZOTTA, 2005).

O Instituto Pestalozzi, fundado em 1926, especializou-se no atendimento assistencialista às pessoas com deficiência mental. Na mesma instituição, no ano de 1945 , foi criado o primeiro atendimento educacional especializado às pessoas com superdotação na Sociedade Pestalozzi, por Helena Antipoff. Em 1954, foi fundada a primeira Associação de Pais e Amigos dos Excepcionais (APAE), no Rio de Janeiro, com o objetivo de prestar serviço em educação, saúde e assistência social à pessoa com deficiência.

Nos anos de 1960, houve um avanço no atendimento educacional às pessoas com deficiência. Sob a Lei n. ${ }^{\circ}$ 4.024/1961, foi instituída a Lei de Diretrizes e Bases que deu aos "excepcionais" o direito ao atendimento, preferencialmente, dentro do sistema geral de ensino. A Lei n. ${ }^{\circ}$ 5.692/1971 altera a Lei n. ${ }^{\circ}$ 4.024/1961 quanto à definição do tratamento especial para os alunos com deficiências físicas, mentais, os que se encontram em atraso considerável em relação à idade regular de matrícula e os superdotados.

Outro evento importante foi a criação do Ministério da Educação e Cultura (MEC) e do Centro Nacional de Educação Especial (CENESP), em 1973. Responsável pela gerência da Educação Especial no Brasil, sob a égide integracionista, impulsionou ações educacionais voltadas às pessoas com deficiência e às pessoas com superdotação, mas ainda configuradas por campanhas assistenciais e iniciativas isoladas do Estado.

A história inicial da Educação Especial no Brasil foi marcada pelo modelo de métodos assistencialistas, com uma visão segregativa e por uma segmentação das deficiências, tornando em muitos momentos a formação escolar e a vida social de pessoas com deficiência. Os movimentos liderados pelos familiares das pessoas com deficiência, por educadores, órgãos governamentais e não governamentais despertaram e forçaram ações que se desdobraram em dispositivos legais que assegurassem os direitos a esse público específico e singular.

A Constituição Federal brasileira de 1988 foi um importante marco para a causa das 
pessoas com deficiência, pois, dentre os seus princípios fundamentais, estão a igualdade de condições e o acesso e permanência na escola de todo o cidadão, independentemente da sua raça, sexo, cor, idade e qualquer condição da pessoa.

Art. 205. A educação como um direito de todos, garantindo o pleno desenvolvimento da pessoa, o exercício da cidadania e a qualificação para o trabalho.

Art. 206, I - igualdade de condições de acesso e permanência na escola.

Art. 208. III - atendimento educacional especializado aos portadores de deficiência, preferencialmente na rede regular de ensino; (BRASIL, 2008).

Com base na referida Constituição, sob a Lei n. ${ }^{\circ}$ 8.069/1990, foi criado o Estatuto da Criança e do Adolescente, cujo conteúdo disposto no art. 55 determina a obrigatoriedade da matrícula de todas as crianças em escolas da rede regular de ensino. Somada a esse documento, a Declaração de Salamanca, criada no ano de 1994, discute pontualmente assuntos referentes à política pública para a Educação Especial.

No mesmo ano, foi estabelecida a Política Nacional de Educação Especial que tem como proposta a "integração instrucional", condicionando o acesso às classes comuns do ensino regular àqueles que:

[...] possuem condições de acompanhar e desenvolver as atividades curriculares programadas do ensino comum, no mesmo ritmo que os alunos ditos normais. Ao reafirmar os pressupostos construídos a partir de padrões homogêneos de participação e aprendizagem, a Política não provoca uma reformulação das práticas educacionais de maneira que sejam valorizados os diferentes potenciais de aprendizagem no ensino comum, mantendo a responsabilidade da educação desses alunos exclusivamente no âmbito da educação especial (BRASIL, 1994 p. 19).

Pelo Decreto n. ${ }^{\circ} 3.298$, que regulamenta a Lei n. ${ }^{\circ}$ 7.853/1999, a Educação Especial passou a ser definida como uma modalidade transversal a todos os níveis e modalidades de ensino, salientando a atuação complementar da Educação Especial ao ensino regular. No mesmo ano, a Convenção da Guatemala estabelece a eliminação de todas as formas de discriminação contra pessoas com deficiência e o favorecimento pleno de sua integração à sociedade.

Define a discriminação como toda diferenciação, exclusão ou restrição baseada em deficiência, ou em seus antecedentes, consequências ou percepções, que impeçam ou anulem o reconhecimento ou exercício, por parte das pessoas com deficiência, de seus direitos humanos e suas liberdades fundamentais, o documento foi retificado pelo Decreto

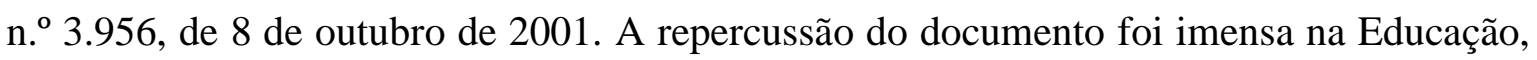
na medida em que passou a exigir uma nova interpretação para a Educação Especial, 
buscando a eliminação das barreiras que impedem a escolarização dessas pessoas.

As Diretrizes Nacionais para a Educação Especial na Educação Básica propõem mudanças por meio da $\mathrm{CNE} / \mathrm{CEB} \mathrm{n} .^{\circ}$ 2/2001, determinando no art. $2 .^{\circ}$ :

Os sistemas de ensino devem matricular todos os alunos, cabendo às escolas organizar-se para o atendimento aos educandos com necessidades educacionais especiais, assegurando as condições necessárias para uma educação de qualidade para todos (BRASIL, 2001).

É importante ressaltar que o Plano Nacional de Educação (PNE), Lei n. ${ }^{\circ}$ 10.172/2001, evidencia o grande avanço da construção de uma escola inclusiva com a seguridade ao atendimento à diversidade humana (BRASIL, 2001).

O ano de 2002 trouxe grandes impactos com relação à legislação. A Resolução $\mathrm{CNE} / \mathrm{CP}$ n. ${ }^{\circ}$ 1/2002 prevê que as instituições de Ensino Superior devam organizar o currículo de maneira a formar docentes voltados para a atenção à diversidade, contemplando conhecimentos específicos para o atendimento de alunos com deficiência. Paralelamente, entra em vigor a Portaria n. ${ }^{\circ}$ 2.678/2002 que aprova as diretrizes e normas para o uso, o ensino, a produção e a difusão do Sistema Braille em todas as modalidades de ensino, compreendendo o projeto da Grafia Braile para a Língua Portuguesa e a recomendação para o seu uso em todo o território nacional.

No ano seguinte, o MEC criou o Programa de Educação Inclusiva: direito à diversidade, que objetiva a reforma dos sistemas de ensino, transformando-os em sistemas educacionais inclusivos, oportunizando um grande processo de formação de gestores e educadores nos municípios brasileiros, para a garantia, a todos, do direito de acesso à escolarização, a organização do atendimento educacional especializado e a promoção da acessibilidade.

O Decreto n. ${ }^{\circ} 5.296 / 2004$ e as Leis n. ${ }^{\circ} 10.048 / 2000$ e n. ${ }^{\circ} 10.098 / 2000$, estabelecem e regulamentam normas e critérios para a promoção de acessibilidade às pessoas com deficiência ou com mobilidade reduzida. Implementação do Programa Brasil Acessível, a Implantação dos Núcleos de Atividade das Altas Habilidades/Superdotação (NAAH/S) em todos os Estados e no Distrito Federal, sendo formados centros de referência para o atendimento educacional especializado aos alunos com altas habilidades/superdotação, a orientação às famílias e a formação continuada aos professores.

No ano de 2005, foi convocada a Convenção sobre os Direitos das Pessoas com deficiência, retificada em 2006, por meio da Convenção sobre os Direitos das Pessoas com Deficiência. Aprovado pela ONU, criou-se o documento que estabelece que os Estados devam assegurar um sistema de educação inclusiva em todos os níveis do ensino, adotando 
medidas para garantir que:

As pessoas com deficiência não sejam excluídas do sistema educacional geral sob alegação de deficiência e que as crianças com deficiência não sejam excluídas do ensino fundamental gratuito e compulsório, sob alegação de deficiência;

As pessoas com deficiência possam ter acesso ao ensino fundamental inclusivo, de qualidade e gratuito, em igualdade de condições com as demais pessoas na comunidade em que vivem (BRASIL, 2005).

O Plano Nacional de Educação em Direitos Humanos (2006) teve por objetivo, entre as suas ações, viabilizar no currículo da educação básica as temáticas relativas às pessoas com deficiência e desenvolver ações afirmativas que oportunizem a inclusão, o acesso e a permanência na educação superior, pela Secretaria Especial dos Direitos Humanos, o Ministério da Educação, o Ministério da Justiça e a Unesco.

No Governo do Presidente Luiz Inácio Lula da Silva, com a implantação do Plano de Aceleração do Crescimento (PAC), em 2007, foi lançado o Plano de Desenvolvimento da Educação (PDE), tendo como objetivos a acessibilidade arquitetônica dos prédios especialmente os escolares, a implantação de salas de recursos e a formação docente para o Atendimento Educacional Especializado (AEE).

O Decreto n. ${ }^{\circ}$ 6.571/2008 do MEC e, posteriormente, o Parecer n. ${ }^{\circ}$ 13/2009, respectivamente, asseguram os recursos de acessibilidade para os alunos com deficiência, transtornos globais do desenvolvimento e superdotação/altas habilidades na educação básica e trataram das diretrizes operacionais para o Atendimento Educacional Especializado para os alunos com deficiência, transtornos globais do desenvolvimento e altas habilidades ou superdotação matriculados em classes regulares e no atendimento educacional especializado. O objetivo do referido parecer é garantir recursos de acessibilidade, bem como estratégias de desenvolvimento da aprendizagem, previstos no projeto político-pedagógico da escola.

Mais recentemente, em 2015, a Lei Brasileira de Inclusão (LBI) foi sancionada, entrando em vigor a partir do dia 2 de janeiro de 2016. A LBI previu mudanças em várias áreas, como o trabalho e a educação, o que se considera um real avanço na inclusão de pessoas com deficiência na sociedade.

Um dos principais pontos dessa lei é o propósito de mudar a perspectiva sobre o conceito de deficiência, que deixa de ser atribuída à pessoa e passa a ser vista como consequência da falta de acessibilidade não só pelo Estado, mas também pela sociedade como um todo. As inovações trazidas pela nova lei alcançaram, entre outras, as áreas de saúde, educação, trabalho, assistência social, esporte, previdência e transporte. Diante 
desse cenário memorável, percebe-se que, apesar de grandes conquistas, a história da educação especial continua sendo escrita, dia após dia, e a escola inclusiva ainda tem um longo caminho a percorrer, principalmente no interior do Brasil.

\section{A cidade de Naviraí - lócus da pesquisa}

A cidade de Naviraí está localizada na região sul do Estado de Mato Grosso do Sul (MS). Considerada o sétimo centro mais populoso de Mato Grosso do Sul e 39. ${ }^{\circ}$ centro mais populoso da região Centro-Oeste do Brasil, o município conta com 53.188 habitantes e 16,66 habitantes por $\mathrm{km}^{2}$, segundo as estimativas de 2017, divididos em 16,441 domicílios, sendo, portanto, uma cidade média-pequena.

O município é conhecido pela sua diversidade cultural, tendo influências japonesas, portuguesas, sul-americanas (paraguaios) e indígenas. A música e a gastronomia são destaques no município de Naviraí. A cidade também é centro episcopal graças a uma diocese presente no município.

Segundo a Fundação de Turismo de Mato Grosso do Sul, o turismo tem sido decisivo no desenvolvimento de Naviraí, em virtude de vários eventos e belezas naturais. $\mathrm{O}$ acesso, por meio de uma rodovia federal a partir da cidade, às principais regiões do Brasil, como os Estados de São Paulo, Paraná, Santa Catarina, Mato Grosso e outros países do Mercosul, facilita as visitas.

No mercado turístico, a cidade faz parte do chamado Cone-Sul de Mato Grosso do Sul. Em uma análise do Ministério de turismo, na infraestrutura turística nacional, a cidade ficou na categoria $\mathrm{C}$ (entre $\mathrm{A}$ e E). Entre as festas turísticas, as mais importantes são o Navi Folia (carnaval de rua do município), Exponavi (Exposição Agropecuária e Industrial de Naviraí, feira mais tradicional do cone-sul do Estado), Fejunavi (festa junina do município) e Nippon Fest (evento baseado na cultura do Japão, com gastronomia e música típicas).

Quanto ao sistema educacional, o município de Naviraí atende alunos do ensino infantil, fundamental, médio e superior. Segundo a Gerência de Educação do município, há 22 escolas no município, sendo 21 na cidade e uma na zona rural. Do total de 259 salas de aula, 255 localizam-se em zona urbana e quatro na zona rural. Em Naviraí, o total de matrículas em 2010 foi de 11.540, sendo 11.449 em zona urbana e 91 na zona rural.

A rede pública de ensino divide-se entre 12 escolas municipais (uma delas na zona rural) e seis escolas estaduais. As escolas somam 131 salas municipais (quatro na zona rural) e 82 salas estaduais. Nestas estão matriculados 4.829 alunos nos estabelecimentos 
estaduais e 6.167 alunos matriculados nos estabelecimentos municipais. Atuam nessa modalidade 253 professores estaduais e 338 professores municipais.

A rede privada é administrada por pessoas jurídicas, sendo representada por quatro unidades com 46 salas de aula. Nessa modalidade, há 544 alunos matriculas e 61

Além disso, o município conta com cinco universidades, sendo três delas públicas, a saber: Universidade Estadual do Mato Grosso do Sul (UEMS), Universidade Federal do Mato Grosso do Sul (UFMS), e Instituto Federal de Mato Grosso do Sul (IFMS); e duas universidades privadas: Faculdades Integradas de Naviraí (FINAV) e Faculdade Anhanguera Educacional.

Das universidades públicas, a UEMS oferta os cursos de Direito, Engenharia de Alimentos e Química. Na UFMS, há os cursos de Administração, Ciências Sociais e Pedagogia. Já o IFMS oferece os cursos de graduação em Agronomia, Tecnologia em Análise e Desenvolvimento de Sistemas.

Nas universidades privadas, os cursos disponíveis são: FINAV - Administração, Ciências Contábeis, Geografia, Letras e Pedagogia; Anhanguera - Administração, Arquitetura e Urbanismo, Artes Visuais (Licenciatura), Ciências Contábeis, Ciências Econômicas, Educação Física (Bacharelado), Educação Física (Licenciatura), Enfermagem, Engenharia Civil, Engenharia da Computação, Engenharia de Produção, Engenharia Elétrica, Engenharia Mecânica, Geografia (Licenciatura), História (Licenciatura), Letras (Licenciatura em Língua Portuguesa e Língua Inglesa), Matemática (Licenciatura), Nutrição, Pedagogia e Serviço Social. Além dos 13 cursos de graduação oferecidos nas universidades, são ofertados 12 diferentes cursos superiores técnicos e tecnológicos.

Dos cursos de graduação, o maior número de procura é para aqueles que oferecem Licenciatura. O curso de Direito da Universidade Estadual do Mato Grosso do Sul tem sido reconhecido em todo o Estado de Mato Grosso do Sul, atraindo estudantes de diferentes partes do Estado e até de outros Estados. Nessa perspectiva educacional, o município de Naviraí tem se despontado como um dos municípios promissores de pesquisas, entre elas, pesquisas acerca da Educação, com temáticas diversas da área, inclusive na área da Educação Especial, temática desta pesquisa.

\section{A Educação Especial em Naviraí}

A Educação Especial no município de Naviraí teve início nos anos 1970. A princípio, as crianças com deficiência, moradoras do município, eram atendidas em uma 
classe especial, localizada no interior do Colégio Marechal Rondon, primeira escola criada no município, no ano de 1956.

Tal atendimento vai ao encontro das propostas nacionais no que tange à Educação Especial, considerando os apontamentos de Capelline e Mendes (2006). As autoras salientam que a criação de serviços ligados à Educação Especial ocorreu nos anos finais da década de 1960. Na década seguinte, 1970, houve uma significativa oferta de ensino a pessoas com deficiência em classes especiais e posteriormente nas Salas de Recursos Multifuncionais (SRM), em especial nas escolas regulares, em sua maioria estaduais (MENDES, 2010).

$\mathrm{Na}$ classe especial do colégio supracitado, eram atendidos alunos com distintas deficiências, mais frequentemente alunos com deficiência intelectual, alunos com Síndrome de Down e com paralisia cerebral. Embora o atendimento fosse oferecido apenas ao aluno com deficiência intelectual leve, devido ao espaço limitado e à carência de materiais adequados para o atendimento a alunos com deficiências graves, mais uma vez o município mostrou-se interessado em avançar nas questões voltadas à Educação Especial.

Conforme Miranda (2008), foi na década de 1970 que a busca pela integração dos "deficientes mentais" (termo utilizado na época) foi evidenciada, permitindo que a Educação Especial tivesse mais visibilidade diante das secretarias educacionais. Para a estudiosa, o atendimento em classes especiais no Brasil, nos anos 1970, era voltado para alunos com deficiências leves, incluindo as "[...] dificuldades de aprendizagem, distúrbios de comportamento e deficiência mental leve" (MIRANDA, 2008, p. 37).

Para que o atendimento especializado fosse efetivado no município de Naviraí, foi necessário que os professores recebessem formação específica. Assim, eles se locomoviam até a cidade de Cuiabá para receber as devidas orientações para desenvolver na sua prática. Os primeiros cursos intensivos nessa área, de nível médio, eram oferecidos em institutos federais, reunindo professores de vários Estados, e, em virtude dessa organização, a carga horária era incerta (ALMEIDA, 2004).

De acordo com uma publicação do jornal O Estado de Mato Grosso, em outubro de 1975, em Cuiabá, ocorreu um seminário com o objetivo de debater as reformas que estavam acontecendo no ensino desde 1971. Entre as reformas, incluíam-se a Educação Especial e o "problema dos excepcionais". O evento foi aberto ao público e teve como participantes autoridades, professores e dirigentes de instituições de ensino.

Em janeiro de 1976, aconteceu, também em Cuiabá, o $1 .^{\circ}$ Encontro de Administração Escolar em Educação Especial, promovido pela Secretaria de Educação e Cultura em parceria com o Centro Nacional de Educação Especial (CENESP), que buscava 
fornecer um auxílio aos interessados em desenvolver programas de Educação Especial. O encontro reuniu pessoas de várias cidades do Estado de Mato Grosso, que já trabalhavam na área em seus respectivos municípios, e discutiram os temas metodologia de trabalho, Psicologia, reabilitação do excepcional, causas da excepcionalidade e relações humanas.

Em 1977, um grupo de pessoas que defendia a causa do excepcional reuniu-se com o firme propósito de fundar a Associação de Pais e Amigos dos Excepcionais (APAE) em Naviraí, sendo eleita em 6 de setembro de 1977 a sua primeira diretoria.

No dia 19 de junho de 1986, a partir das ações da APAE, foi criado o Centro de Educação Especial Naviraiense (CEDEN), oferecendo os programas de atendimento: estimulação essencial, habilitação e reabilitação. Inicialmente, o CEDEN atendeu 23 alunos, mesmo sem qualquer tipo de triagem. O único profissional capaz de fazer uma avaliação era um fisioterapeuta da cidade, cujo trabalho era voluntário. As professoras cedidas pela rede de ensino municipal, além de sua função docente, limpavam o ambiente e preparavam a merenda das crianças, tal era a escassez da mão de obra.

Somente no dia $1 .^{\circ}$ de março de 1996 , alunos e funcionários instalaram-se no prédio próprio da APAE, na rua Mato Grosso n. ${ }^{\circ}$ 1.385. Nessa data, a instituição atendia 83 alunos, contava com 15 professores cedidos pela Secretaria do Estado de Educação de Mato Grosso do Sul e duas professoras pagas pela própria APAE.

Atualmente, a instituição conta com o atendimento dos seguintes profissionais: fisioterapeuta, psicóloga, fonoaudióloga, médica pediatra, professores de educação infantil, fundamental, artes visuais, artes cênicas, educação física, diretora, coordenador, além da equipe administrativa, secretária, motorista, cozinheira e auxiliares de serviços diversos. Os alunos são avaliados com todos os critérios necessários, de acordo com a especialidade de cada técnico, e encaminhados para os profissionais adequados, bem como para professores que os acompanharão em suas necessidades pedagógicas.

Observa-se que, desde os primeiros atendimentos aos deficientes no Colégio Marechal Rondon, a população naviraiense se organizou para que fosse incluído esse público. A criação da APAE no município tornou-se um marco, cujo atendimento aproxima-se de 30 anos.

Quanto ao Atendimento Educacional Especializado nas escolas de Naviraí, o município tem buscado, na medida do possível, cumprir as diretrizes operacionais estabelecidas pela Resolução CNE/CEB n. ${ }^{\circ}$ 4/2009, principalmente no que tange ao art. 5. : 
O AEE é realizado, prioritariamente, nas salas de recursos multifuncionais da própria escola ou em outra de ensino regular, no turno inverso da escolarização, não sendo substitutivo às classes comuns, podendo ser realizado em centro de atendimento educacional especializado de instituição especializada da rede pública ou de instituição especializada comunitárias, confessionais ou filantrópicas sem fins lucrativos, conveniadas com a secretaria de educação ou órgão equivalente dos estados, do Distrito Federal ou dos municípios (BRASIL, 2009).

Conforme a Coordenadora de Inclusão do município de Naviraí, a partir do questionário aplicado, o munícipio tem se empenhado para atender aos alunos que necessitam de cuidado especializado da melhor forma possível:

\begin{abstract}
A sala de Recursos é um espaço que contribui de forma significativa para a aprendizagem destes alunos. Atualmente o município conta com duas Salas de Recursos Multifuncionais que funcionam tanto no período matutino quanto vespertino. Cada uma dessas salas atende vinte alunos por período, sendo que são divididos dois dias por semana e duas horas cada atendimento por semana, cada grupo. Não são todos que frequentam esta sala devido elas estarem funcionando em duas escolas apenas (Coordenadora de Inclusão do município de Naviraí - questionário respondido em 16.10.2018).
\end{abstract}

Para a gestora, as SRM têm sido um espaço importante, cuja contribuição é significativa para o aluno com deficiência, entretanto "não são todos os que frequentam esta sala...”, pois o número de SRM ainda é insuficiente para a demanda no município. Embora o atendimento nas SRM tenha a sua relevância no atendimento ao aluno com deficiência, compreende-se que o processo de inclusão escolar perpassa por outras ações, as quais dependem de implementação de políticas estruturantes nos sistemas de ensino que altere a organização da escola, de modo a superar os modelos de integração em escolas e classes especiais.

Nesse sentido, a escola deve cumprir a sua função social, construindo uma proposta pedagógica capaz de valorizar as diferenças, com a oferta da escolarização nas classes comuns do ensino regular e do atendimento às necessidades específicas dos seus alunos. Essa concepção está expressa nas Diretrizes Nacionais da Educação Básica, instituídas pela Resolução CNE/CEB n. ${ }^{\circ}$ 4/2010, conforme disposto no seu art. 1. ${ }^{\circ}$ :

Os sistemas de ensino devem matricular os estudantes com deficiência, transtornos globais do desenvolvimento e altas habilidades/superdotação nas classes comuns do ensino regular e no atendimento educacional especializado (AEE), complementar ou suplementar à escolarização ofertado em sala de recursos multifuncionais ou em centros de AEE da rede pública ou de instituições comunitárias, confessionais ou filantrópicas sem fins lucrativos (BRASIL, 2010). 
Com base na referida Resolução, acredita-se que todos os alunos, público-alvo da Educação Especial, devem ser matriculados nas classes comuns, em uma das etapas, níveis ou modalidade da educação básica, sendo o AEE ofertado no turno oposto ao do ensino regular. Assim, faz-se se necessária a ampliação das Salas de Recursos no município de Naviraí e, ademais, a capacitação de um maior número de professores para realização do atendimento especializado.

Nesse ponto, a Gerência Municipal de Educação de Naviraí menciona que os(as) estagiários(as), acadêmicos(as) dos cursos de Pedagogia atuam como professores de apoio, cuja nomenclatura para o serviço prestado é: itinerante. A única exigência para o acadêmico atuar como itinerante é estar matriculado em um curso de graduação em Pedagogia.

Os dados do questionário, respondido pela gestora, apontam que os professores titulares, regentes das salas regulares, que têm alunos com deficiências e/ou transtornos, possuem formações superiores em suas áreas específicas, alguns têm especialização em Educação Especial, bem como em outras áreas. Também há profissionais que cursaram ou estão cursando Mestrado e Doutorado. Exceto a exigência da formação específica para a área de atuação, os cursos em nível de especialização são, na maioria das vezes, opções dos professores, para o próprio aprimoramento profissional e intelectual.

Esse aprimoramento é necessário para o professor que tem, em sua sala de aula, um aluno com deficiência, pois, a partir da sua formação, adquire conhecimento de que para atendê-lo de forma inclusiva não pode se limitar a planejamentos-padrão. Pelo contrário, as necessidades específicas desse aluno geram a necessidade de novas e diferentes formas de apresentar o conteúdo escolar, ação que proporciona maior compreensão por parte desse aluno e dos demais.

No art. 59 da LDB/1996, a preparação de professores para atuarem com essas especificidades preconiza que:

Os sistemas de ensino assegurarão aos educandos com necessidades especiais: [...] III - professores com especialização adequada em nível médio ou superior, para atendimento especializado, bem como professores do ensino regular capacitados para a integração desses educandos em classes comuns (BRASIL, 1996, p. 27).

$\mathrm{Na}$ cidade de Naviraí, conforme as respostas da Coordenadora de Inclusão, os alunos com deficiência têm um professor de apoio na sala de aula, contudo, por serem professores itinerantes, eles não recebem uma formação específica, pois ainda estão em formação na graduação: 
Em sala de aula que consta um aluno com deficiência é direcionada uma itinerante, a qual estará contribuindo para com a professora da sala, com o intuito de que a mesma tenha um tempo maior para atender o aluno especial. Os itinerantes recebem orientações de como agir em sala de aula. Não existe uma formação específica, somente algumas reuniões bimestrais para esclarecer o papel das mesmas em sala e sanar algumas dúvidas pertinentes a suas funções (Coordenadora de Inclusão do município de Naviraí - questionário respondido em 16.10.2018).

A coordenadora de Inclusão do município de Naviraí complementa:

$\mathrm{Na}$ verdade compreendemos que para acontecer a inclusão há necessidade de uma transformação do sistema educacional, mais flexível, aberto a mudanças, no entanto, hoje, ainda permanecem algumas orientações aos professores do ensino regular, pelo coordenador da escola ou pela coordenadora de inclusão de trabalhar conteúdos, os quais os alunos estão apresentando dificuldades, independente da série que se encontra. Professores não recebem formação específica (Coordenadora de Inclusão do município de Naviraí - questionário respondido em 16.10.2018).

Nos dois apontamentos supracitados, a Coordenadora diz que os profissionais que atuam com alunos com deficiência no município não recebem nenhuma formação continuada específica, tendo como proposta que a Educação Básica deve ser inclusiva. Para atender a uma política de inclusão dos estudantes com necessidades educacionais especiais nas classes comuns dos sistemas de ensino, é preciso que os professores estejam em constante formação, visto serem eles os responsáveis pelo desenvolvimento desses alunos no que diz respeito à educação escolar.

Nessa direção, é fundamental que o professor esteja preparado para receber o "novo aluno", para que a inclusão não seja somente física, mas em todos os âmbitos que proporcionem uma aprendizagem significativa para todos os alunos. Para que ocorra uma efetiva aprendizagem é necessário conhecer o professor, compreender o que ele pensa, saber quais suas expectativas e até mesmo seus receios e ansiedades com relação ao diferente.

Com o intuito de acompanhar mais de perto o processo de inclusão escolar no município, a Coordenadora de Inclusão do município de Naviraí destaca, ao responder o questionário, que no início de 2018 fez um levantamento nas escolas com o objetivo de mapear o número de alunos que necessitavam de atendimento especializado e de um professor itinerante para apoiá-los nas suas necessidades:

No início deste ano letivo, fizemos um levantamento nas escolas, a fim de sabermos a quantidade de alunos com laudo e que necessitam de apoio itinerante, para avançarem em suas aprendizagens. Em março de 2018 a 
demanda era de 86 alunos no ensino fundamental, os quais frequentam desde o primeiro ano do Ensino Fundamental até o nono ano do Ensino Fundamental, sendo que suas idades variam de sete a dezoito anos. Na Educação Infantil estão sendo atendidos 23 alunos e todos contam com itinerantes (Coordenadora de Inclusão do município de Naviraí questionário respondido em 16.10.2018).

O levantamento realizado nas escolas também possibilitou que fossem identificados os tipos de deficiências e de transtornos atendidos pela rede municipal, conforme aponta a gestora:

As deficiências mais comuns encontradas nas escolas municipais são alunos com deficiência intelectual, em seguida com síndrome de Asperger, que agora é diagnosticada como transtorno do espectro do autismo, podemos considerar uma forma branda do autismo, síndrome de Down e TOD - Transtorno Opositor Desafiador (Coordenadora de Inclusão do município de Naviraí - questionário respondido em 16.10.2018).

Como no início do processo da Educação Especial, o município de Naviraí ainda atende muitos alunos com deficiência intelectual, no entanto percebe-se pela resposta da Coordenadora que alunos com Transtorno do Espectro Autismo são os mais comuns a serem atendidos pela rede. Acredita-se que isso ocorre após a garantia dos direitos a esses alunos, bem como sua inserção na Educação Especial.

A legislação brasileira confere especial proteção à pessoa com autismo, garantindo inúmeros direitos a essa parcela da população. A Lei n. ${ }^{\circ}$ 12.764/2012, conhecida como Lei Berenice Piana, instituiu a Política Nacional de Proteção dos Direitos da Pessoa com Transtorno do Espectro Autista e foi a primeira a considerar o autista uma pessoa com deficiência. Mais recentemente, foi editada a Lei n. ${ }^{\circ}$ 13.145/2015, a Lei Brasileira de Inclusão da Pessoa com Deficiência, mais conhecida como Estatuto da Pessoa com Deficiência. Sendo considerado pessoa com deficiência, o autista é destinatário dos direitos previstos no Estatuto.

A partir do conceito de inclusão, a Coordenadora de Inclusão do município de Naviraí explica que esta é feita da seguinte forma:

Normalmente quando a professora percebe que algum aluno não está acompanhando o processo de aprendizagem da mesma forma que os demais, encaminhamos para uma avaliação Psicopedagógica, para uma segunda opinião, diante do resultado apresentado pelos testes, o aluno é direcionado para as salas de recursos, ou quando percebe-se uma dificuldade acentuada orientam-se os pais a procurar um neurologista (Coordenadora de Inclusão do município de Naviraí - questionário respondido em 16.10.2018). 
A Coordenadora diz que o processo de inclusão acontece por meio do encaminhamento dos alunos que não estão acompanhando o processo de aprendizagem para uma avaliação psicopedagógica e, posteriormente, conforme resultados da avaliação, os alunos são direcionados para a sala de recurso. Entretanto, sabe-se que o conceito de inclusão vai muito além, pois a escola deve ser o espaço que favoreça a todos os cidadãos o acesso ao conhecimento e o desenvolvimento de competências, ou seja, a possibilidade de apropriação do conhecimento sem nenhuma barreira, e cabe a essa escola estar adaptada e equipada com recursos arquitetônicos, humanos e pedagógicos para receber todas as pessoas que compõem a diversidade dessa sociedade.

A gestora pontua que o atendimento e o apoio da professora itinerante não se limitam apenas aos alunos que possuem laudos, mas também são oferecidos atendimentos aos alunos que apresentam uma dificuldade na sua aprendizagem e que por motivos diversos não possuem o documento.

Todos os alunos que estão na rede municipal que tem uma itinerante, nome dado às acadêmicas que auxiliam a professora que tem aluno com deficiência, apresentaram laudo. Há alguns casos de alunos que apresentam dificuldades acentuadas de aprendizagem que não têm laudo, nestes casos são oferecidas vagas na sala de recursos, uma forma encontrada para amenizar a dificuldade apresentada pelo aluno (Coordenadora de Inclusão do município de Naviraí - questionário respondido em 16.10.2018).

Conforme a Nota Técnica n. ${ }^{\circ}$ 4/2014 do Ministério da Educação (MEC), não se pode considerar imprescindível a apresentação de laudo médico, uma vez que o AEE se caracteriza por atendimento pedagógico, e não clínico. Assim, exigir o laudo do estudante para declará-lo público-alvo da Educação Especial e, desse modo, garantir-lhe o atendimento de suas especificidades educacionais é impor barreiras ao seu acesso aos sistemas de ensino.

Ainda, segundo a resposta da Coordenadora do município de Naviraí, a sala de recursos atende "alunos com dificuldades acentuadas de aprendizagem", no entanto, conforme o Programa de Implantação de Salas de Recursos Multifuncionais, instituído pelo MEC/SEESP, por meio da Portaria Ministerial n. ${ }^{\circ}$ 13/2007, que integra o Plano de Desenvolvimento da Educação (PDE), destina-se o apoio técnico e financeiro aos sistemas de ensino para garantir o acesso ao ensino regular e a oferta do AEE aos alunos com deficiência, transtornos globais do desenvolvimento e/ou altas habilidades/superdotação.

De acordo com as orientações da Secretaria de Educação Continuada, Alfabetização, Diversidade e Inclusão, por meio da Diretoria de Políticas de Educação 
Especial (Secadi/DPEE), os estudantes devem ser categorizados no Censo Escolar da Educação Básica, constando se pertencem ou não ao público-alvo da Educação Especial.

A Secretaria de Educação Continuada, Alfabetização, Diversidade e Inclusão, por meio da Diretoria de Políticas de Educação Especial (SECADI/DPEE) diz que pessoas que apresentam transtornos funcionais específicos, como Transtorno de Déficit de Atenção com Hiperatividade (TDAH), Transtorno de Déficit de Atenção (TDA) e Dislexia não são considerados como público-alvo, portanto as informações sobre estes não são coletadas no Censo.

Embora se observe que a inclusão escolar no município de Naviraí necessita de ações para que cumpra todos os dispositivos legais voltados para essa perspectiva, verificase que desde o início a sociedade naviraiense já se preocupava com as pessoas com deficiência, resultando na criação da APAE e sua ampliação. A partir de então, a rede educacional do município tem buscado possibilidade para incluir os seus alunos com necessidades especiais nas classes normais, bem como proporcionado o atendimento nas SRM e o apoio de um professor itinerante, ainda que este esteja em formação.

Os destaques feitos pela Coordenadora de Inclusão do município de Naviraí no questionário aplicado demonstram que, embora os desafios sejam gigantes, os caminhos para que a educação no município seja inclusiva já estão sendo percorridos.

\section{Considerações finais}

A história e os desdobramentos da Educação Especial no município de Naviraí nasceram do interesse da comunidade, o que resultou na criação da APAE nos anos 1970 e no atendimento à criança deficiente em uma classe especial nas dependências do Colégio Marechal Rondon.

A demanda de atendimento especializado para os alunos com deficiência levou o sistema de educação local a buscar subsídio que aperfeiçoasse e ampliasse o atendimento a esse público específico. Assim, os professores buscaram a sua formação na área em cursos existentes na cidade de Cuiabá/MT, oferecidos por órgãos federais. A ampliação das SRM veio para possibilitar um maior número de crianças atendidas, embora ainda não se estenda a todas as crianças com necessidades especiais.

Entre os desafios para o processo de inclusão escolar dos alunos com deficiência está a capacitação específica dos professores, em especial ofertada pelo sistema público de ensino. Enquanto isso, estagiários do curso de Pedagogia atendem aos alunos, com necessidades especiais, como apoio itinerante. Ainda que haja delimitações específicas, 
por exemplo, a exigência do laudo para o atendimento do aluno na SRM, é garantido aos alunos que apresentam dificuldades de aprendizagem o acesso a essas salas, uma vez que o interesse é auxiliá-los em suas dificuldades.

Portanto, observa-se que, mesmo em face de tantos desafios acerca da inclusão escolar no município de Naviraí, os seus gestores educacionais têm buscado de alguma forma contemplar as necessidades dos alunos público-alvo da Educação Especial, dandolhes possibilidade de desenvolver suas capacidades e potencialidades.

\section{REFERÊNCIAS}

ALMEIDA, Maria Amélia. Formação do professor para a educação especial: história, legislação e competências. Revista Educação Especial, Santa Maria, n. 24, p. 1-7, 2004.

BRASIL. Lei n. ${ }^{\circ}$ 4.024, de 20 de dezembro de 1961. Fixa as diretrizes e bases da educação nacional. Disponível em: http://www.planalto.gov.br/ccivil_03/leis/ L4024.htm. Acesso em: 20 jan. 2017.

BRASIL. Lei n..$^{\mathbf{5 . 6 9 2}}$, de 11 de agosto de 1971. Fixa as diretrizes e bases para o ensino de 1. e 2.graus, 1971. Disponível em: http://www.planalto.gov.br/ccivil_03/leis/L5692.htm. Acesso em: 20 jan. 2017.

BRASIL. Constituição da República Federativa do Brasil. Brasília, 1988.

BRASIL. Lei $\mathbf{n}^{\mathbf{0}} \mathbf{7 . 8 5 3}$, de 24 de outubro de 1989. Dispõe sobre o apoio às pessoas portadoras de deficiência, sua integração social, sobre a Coordenadoria Nacional para Integração da Pessoa Portadora de Deficiência. Disponível em: http://www.planalto.gov.br/ccivil_03/leis/L7853.htm. Acesso em: 20 jan. 2017.

BRASIL. Lei n. ${ }^{\circ}$ 8.069, de 13 de julho de 1990. Dispõe sobre o Estatuto da Criança e do Adolescente. Brasília: CBIA, 1990.

BRASIL. Lei n. 9 9.394/1996. Lei de Diretrizes e Bases da Educação Nacional. Brasília, 1996.

BRASIL. Resolução CNE/CEB n. ${ }^{\circ}$ 2, de 11 de setembro de 2001. Institui diretrizes nacionais para a educação especial na educação básica. Disponível em:

http://portal.mec.gov.br/cne/arquivos/pdf/CEB0201.pdf. Acesso em: 20 jan. 2017.

BRASIL. Ministério da Educação. Secretaria de Educação Especial. Política Nacional de Educação Especial. Brasília: MEC/SEESP, 1994.

BRASIL. Lei.$^{\circ}$ 5.626, de 22 de dezembro de 2005. Regulamenta a Lei n. ${ }^{\circ} 10.436$, de 24 de abril de 2002, que dispõe sobre a Língua Brasileira de Sinais - Libras, e o art. 18 da Lei n. ${ }^{\circ}$ 10.098, de 19 de dezembro de 2000. Brasília: CBIA, 2005. 2019.

. Resolução no 4, de 13 de julho de 2010. Ministério de Educação. Brasília: MEC, 
BRASIL. Resolução no 4, de 2 de outubro de 2009. Ministério da Educação. Brasília: MEC, 2009.

BRASIL. INEP. Censo Escolar, 2006. Disponível em:

http://www.inep.gov.br/basical/censo/default.asp. Acesso em: 20 jan. 2007.

BRASIL. Ministério da Educação. Política Nacional de Educação Especial na

Perspectiva da Educação Inclusiva, 2008. Disponível em:

http://portal.mec.gov.br/arquivos/pdf/politicaeducespecial.pdf. Acesso em: 20 jan.

2017.

BRASIL. Lei n. ${ }^{\circ}$ 13.146, de 6 de julho de 2015. Institui a Lei Brasileira de Inclusão da Pessoa com Deficiência. Brasília: CBIA, 2015.

BRASIL. Lei n. ${ }^{\circ}$ 13.409, de 28 de dezembro de 2016. Altera a Lei n. $^{\circ} 12.711$, de 29 de agosto de 2012, para dispor sobre a reserva de vagas para pessoas com deficiência nos cursos técnico de nível médio e superior das instituições federais de ensino. Brasília: CBIA, 2016.

CAPELLINI, Vera Lucia Messias Fialho; MENDES, Enicéia Gonçalves. História da educação especial: em busca de um espaço na história da educação brasileira. In: SEMINÁRIO NACIONAL DE ESTUDOS E PESQUISAS, 7., 2006, Campinas. Anais... Campinas: Faepex - Unicamp, 2006. v. 1.

CRIANÇA EM DESENVOLVIMENTO. Diretrizes nacionais para a educação especial na educação básica. Resolução CNE/CEB n. ${ }^{\circ}$ 2, MEC, 2001.

CRIANÇA EM DESENVOLVIMENTO. Estratégias e orientações pedagógicas para a educação de crianças com necessidades educacionais especiais. Dificuldades acentuadas de aprendizagem. Deficiência múltipla. Brasília: MEC, 2002.

CRIANÇA EM DESENVOLVIMENTO. Educação inclusiva e formação docente. Disponível em: https://diversa.org.br/artigos/educacao-inclusiva-e-formacao-docente/. Acesso em: 22 out. 2018.

\section{CRIANÇA EM DESENVOLVIMENTO. Inclusão sem laudo é direito da Criança!}

Disponível em: https://emais.estadao.com.br/blogs/crianca-em-

desenvolvimento/inclusao-sem-laudo-e-um-direito-da-crianca/. Acesso em: 18 jun. 2018.

IBGE. Cidades. Brasil. Mato Grosso do Sul. Naviraí. 2017. Disponível em: https://cidades.ibge.gov.br/brasil/ms/navirai/historico. Acesso em: 20 jan. 2017.

MARCONI, Marina de Andrade; LAKATOS, Eva Maria. Fundamentos de metodologia científica. 5 ed. São Paulo: Atlas, 2003.

MATO GROSSO. Secretaria de Educação e Cultura. Centro Nacional de Educação Especial - Cenesp. Primeiro Encontro de Administração Escolar em Educação Especial. Cuiabá, MT, 1976.

MAZZOTTA, Marcos José da Silveira. Educação especial no Brasil: história e políticas públicas. 5. ed. São Paulo: Cortez, 2005. 
MENDES, Enicéia Gonçalves. Breve histórico da educação especial no Brasil. Revista Educación y Pedagogía, Medellín, v. 22, n. 57, p. 93-109, mayo/ago. 2010.

MINISTÉRIO DA EDUCAÇÃO. Secretaria de Educação Especial. Manual de Orientação: Programa de Implantação de Sala de Recursos Multifuncionais. Disponível em: http://portal.mec.gov.br/index.php?option=com_docman\&view=download\&alias=9936manual-orientacao-programa-implantacao-salas-recursos-multifuncionais\&Itemid=30192. Acesso em: 20 out. 2018.

MIRANDA, Arlete Aparecida Bertoldo. Educação especial no Brasil: desenvolvimento histórico. Cadernos de História da Educação, Uberlândia, n. 7, p. 29-44, jan./dez. 2008.

\section{Como referenciar este artigo}

ALVES BARBOSA, Felipe; SARAMAGO DE SOUZA, Ilma Regina Castro. Educação especial no município de Naviraí-MS: história, desdobramentos e desafios para a inclusão escolar. Doxa: Rev. Bras. Psico. e Educ., Araraquara, v. 21, n. 2, p. 314-333, jul./dez. 2019. e-ISSN: 2594-8385. DOI: https://doi.org/10.30715/doxa.v21i2.13103

Submetido em: 20/02/2019

Aprovado em: 20/07/2019

Publicado em: 01/08/2019 